\title{
An Investigating on UGC Adoption in Web 2.0 Environment: Antecedents and Consequences
}

\author{
Lei Shen, Yaning Zhang, Shaofeng Yue \\ School of Glorious Sun Management, Donghua University, Shanghai, China \\ Email: zhangyn_isla@qq.com
}

How to cite this paper: Shen, L., Zhang, Y. N., \& Yue, S. F. (2020). An Investigating on UGC Adoption in Web 2.0 Environment: Antecedents and Consequences. American Journal of Industrial and Business Management, 10, 1058-1072.

https://doi.org/10.4236/ajibm.2020.105070

Received: May 6, 2020

Accepted: May 26, 2020

Published: May 29, 2020

Copyright $(0) 2020$ by author(s) and Scientific Research Publishing Inc. This work is licensed under the Creative Commons Attribution International License (CC BY 4.0).

http://creativecommons.org/licenses/by/4.0/

\section{(c) (i) Open Access}

\begin{abstract}
Purpose: The purpose of this paper is to investigate the adoption model of user-generated content in Web 2.0 Internet environment. The author hopes to verify the quality of user-user interaction, and test the influence of such interaction on users' perceived usefulness and adoption willingness. Design/Methodology/Approach: The influence of user generated content on e-commerce websites has been addressed in both practical and theoretical fields. This study focuses on the connotation of prosumption behavior and the quality of user-user interaction through qualitative research. It clarifies the mechanism of user interaction and counterproductive behavior in the Web 2.0 Internet platform for those from the double process theory perspective of Elaboration Likelihood Model (ELM). This study has investigated quantitatively. The authors used structural equations modeling on 58 users (21 offline and 37 online users of book.douban). Findings: Firstly, the results emphasized the effect of user-user interaction quality on user information usefulness and information willingness. In addition, the research results also proved that users' perceived usefulness of UGC information and the willingness of UGC adoption have played a positive role in users' subsequent prosumption behavior. Finally, we applied our theoretical findings to derive managerial implications. Originality/Value: This paper not only revealed quantitatively the nature of prosumption behavior and quality of user-user interaction, but also figured out the antecedents and consequences of information adoption.
\end{abstract}

\section{Keywords}

User-Generated Content, Information Adoption, Prosumption, Web 2.0

\section{Introduction}

Web 2.0 emerged from a brainstorm in 2004 (O'eilly, 2005), then altered the 
culture of the Internet era by its uniqueness. Compared with Web 1.0, the latter concentrated on technological innovation and based on the model of profiting from huge click rates, and Web 2.0 emphasizes the openness and divergence of platforms. In Web 2.0, user-user interactions appreciate and users play the role of not only the "consumer" of information but also the "producer" of massive data. In short, users browse information and enjoy sharing thoughts and opinions with one another all over the world.

Furthermore, such production and consumption of information has been gradually playing an important role in the Internet economy in a collectively created and shared way, and has also become an indispensable part in the enterprise marketing strategy to achieve "low cost and high benefit". For example, Xiaomi got its first 500,000 MIUI consumers mostly from online forums; Amazon surpasses competitors in sales thanks to its one-order-of-magnitude-more users, etc. The leader of Web 1.0 era who has relied on technological innovation and traffic breakthroughs want to continue leading the user as the king of Web 2.0, the key is to correctly understand the user-generated content and users' prosumption, and create more economic value.

It will be an exciting research if we can figure out the factors that affect users' perception towards the content usefulness/value, and how these factors affect the users' adoption willingness and promote the users to continue participating information prosumption. Although the issue of information adoption has been explored a lot, the subsequent prosumption behaviors after adoption have not been paid enough attention. This paper uses qualitative research to understand the concept of prosumption behavior and the connotation of the quality of user-user interaction, and proposes an adoption model about user-generated content under Web 2.0 environment. The results of this study via structural equation analysis provide corresponding suggestions and inspiration for future enterprise management and the related theoretical research.

\section{Literature Review of Prosumption and Adoption}

\subsection{Prosumption Behavior in Web 2.0}

The prosumption phenomenon is becoming more and more popular in the academic world. Since the last two decades, several concepts have been used to investigate the continuous reconfiguration of the classic production paradigm. The general focus of prior prosumption research is on identifying desired outcomes, not how the decision to prosume is made. Ritzer (2014) conceptualised the term prosumption as a continuum of both production and consumption. Over the past decade, prosumption has dramatically expanded, due to the internet, Web 2.0 , and consumers' newfound ease of access to the production side of consumption (manufacturing, design, and distribution) and the consequent new freedom firms found over consumers (Rayna and Striukova, 2015). Lan et al. (2017) illustrated this prosumption phenomenon with the case study of Mobike Company and its consumer as "user A" (Lan et al., 2017). One exception is Wolf and Mc- 
Quitty (2015), which examines the motivation to prosume (e.g. economic benefit, lack of product quality and lack of product availability) of individuals who personally identify as do-it-yourselfers.

The research team of Dr. Shen et al. (Shah, Shen, Hussain, \& Mariam, 2019) reviewed literature on prosumption behavior, prosumers are knowledgeable, empowered consumers who use digital technology (Web 2.0) to collaborate and participate in product or service design, conception, testing, and usage, and they have a significant influence on their social networks and communities. This means that prosumers are participating in their active role in organization-sponsored sharing platform under sharing economy. The similar response can be observed by the rise of popular media outlets such as HGTV (Home and Garden TV) and the DIY (do-it-yourself) network that promotes the trend toward self-production, and virtual prosumers who add, like, dislike or modify online contents on facebook and Wechat. It is obvious from the above illustrations that digital technologies have a significant effect on prosumers, but due to dramatic technological advancement, human prosumer will be gradually replaced with prosuming machines in the near future (Ritzer, 2015). The research team of Dr. Shen \& Zheng (Shen and Zheng, 2014) reviewed literature on consumption behavior, information consumption and internet consumption and illustrated three consumption behaviors in the commercial age of Web 2.0 from the perspectives of participation and contribution (see Figure 1). The aforesaid

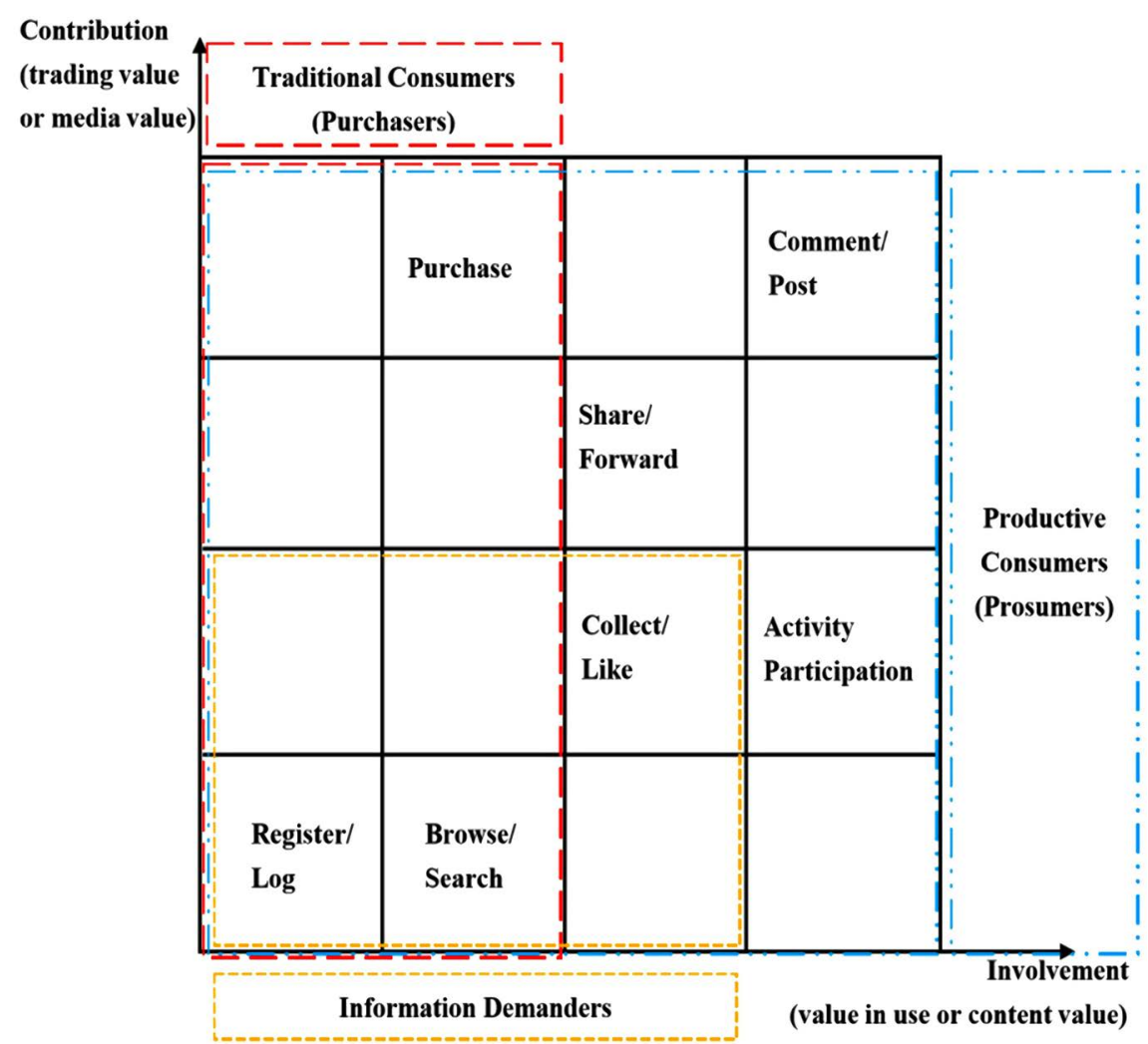

Figure 1. The essence of online consumer behavior in Web 2.0 era. 
behaviors are: 1) Information Demanders: purposeless information reception or purposeful one-way information retrieval (e.g. browse, add to Favorite, and thumb-up); 2) Purchasers: purposeful one-way and static information retrieval to filter and purchase commodities (e.g. search, browse and purchase); 3) Prosumers: productive consumption featuring information interaction, production, dissemination and commodity purchase (e.g. review, post, share and purchase).

\subsection{Information Adoption Model}

As Web 2.0 progresses, shopping and socializing are integral to our lives. Users post-experience and opinions on certain topics or commodities freely, while others help them make better decisions via searching and judging the relevant information on network platforms. Reviews posted online regarding eBay or Amazon can affect buyers' expectations concerning their potential interactions with those sellers (Tsao, 2017). However, usually only useful reviews can help consumers make better behavior decisions (Tan and Lee, 2018). Network platforms cannot attract or keep consumers by only providing reviews. Only when information providers offer highlighted useful contents will users locate most quickly the contents that are the most valuable to their further decisions, then the users can adopt the information and implement final behavior.

\subsection{Emergence of Information Adoption}

Pioneered by seminal work, word-of-mouth (WOM) communication is considered a valuable marketing resource for both consumers and marketers. Traditional WOM communication is defined as all informal exchange of information among consumers about the characteristics, usage, and ownership of products and services, and it is considered a major driver of consumer adoption and diffusion of new products, particularly for late adopters ( $\mathrm{Hu}$, Pavlou, \& Zhang, 2006). Traditional WOM and its influence is limited to a local network of people (Li and Hong, 2008), while the information produced through online platforms has no geographical restrictions and can be accessible worldwide (Park et al., 2007). The concept of information adoption on Web 2.0 has emerged.

Information adoption can be defined as the process of engaging purposefully in consuming information (Cheung and Thadani, 2012). When consumers search for information provided by other users on online communities to make a better decision for their purchasing, they are adopting information. Chevalier and Mayzlin (2006) examined the effect of online product reviews on book sales on Amazon's and Barnes and Noble's websites, showing that an improvement in a book's online product reviews enhances book sales. So it proves the importance of online commentary on purchase behavior.

\subsection{Impact Factors of Information Adoption}

Meanwhile, previous research on users' information adoption centered on the influence that critical cues (e.g. information quality) and peripheral cues (e.g. 
source credibility) yield on users' perceived usefulness and adoption willingness. Some Research shows that information quality has a strong impact on the decision of users to adopt WOM provided in the online communities (Cheung et al., 2008). Once individuals perceive more value, they are more likely to become involved in online WOM (Yeh and Wang, 2017). Perceived usefulness has become increasingly important with the growth in the number of SNSs and the opportunities that social media provides. Other Research shows that credibility of the information on Web 2.0 has a significant value for the success of purchase behavior. The higher source credibility of messages perceived in online communities provides a higher level of information adoption (Zhao et al., 2019). Given their differences in product knowledge level, the credibility of other consumers is an important non-content cue for consumers making purchase decision ( $\mathrm{Zhu}$, Chang, and Luo, 2016). In addition, previous research was mostly grounded on Web 1.0 where $\mathrm{B} 2 \mathrm{C}$ is the major interaction model and e-mail information exchange channel. User-user interaction, feature of Web 2.0, were hardly explored. On one hand, the information adoption model could only reach to the advent of adoption willingness without digging deeper about the influence on users' consequent behaviors, prosumption behavior in particular. On the other hand, in Web 2.0 (especially social network sites) featuring user-user interaction, scholars haven't marched beyond the definition of prosumption behavior, and Chinese scholars have paid little attention to the potential economic value brought about by prosumption behavior.

To sum up, this paper attempts to address the following problems: 1) Based on the qualitative research of prosumption behavior (Shen and Zheng, 2014; Ritzer, 2015) in the Web 2.0 business era, this paper verifies the connotation of this brand-new concept via empirical exploration; 2) Grounded on the interaction of Web 2.0, this paper aims to verify the quality of user-user interaction, and test the influence of such interaction on users' perceived usefulness and adoption willingness; 3) This paper probes into the influence that users' perceived usefulness and adoption willingness yield on their subsequent prosumption behavior, thus enriching the information adoption model.

\section{Research Method}

Two studies have been designed in this research. In study1, using a grounded theory approach, the authors investigated the nature and consequences of user-user interaction quality. Further, the quantitative studies have been conducted to uncover the different elements of "quality of user-user interaction" and "prosumption behavior". The authors used structural equations modeling on survey data to explore how these elements can be modeled as both first-order and higher-order structural models. In study 2, UGC adoption model and mediating role of adoption willingness have been explored. In addition, "quality of user-user interaction" as an antecedent of information adoption willingness and prosumption behaviors as consequences have been discussed systemati- 
cally.

\section{Study 1}

We choose the users from Book.DouBan, a social network website featuring both message interaction and online shopping, as our research objects. The purpose of study 1 is to explore two major concepts-"quality of user-user interaction" and "prosumption behavior" via qualitative research and empirical test, so as to plan for sound measurement on theoretical constructs, thereby laying a theoretical foundation for the subsequent works.

\subsection{Questionnaire Design and Sample Selection}

The survey is based on open-ended questionnaires of both basic information (gender and age) and topics of "quality of user-user interaction". Thus to ensure that respondents feel free to answer without being interfered by phrases like "I think the XX you mentioned is useful/useless".

Owing to the great geographical dispersion of users, specific survey was consequently conducted on 58 users ( 21 offline and 37 online users of book.douban).

This paper conducted initial coding and axial coding on the data collected from interviews, and then gradually identified certain critical topics for classification according to the quality of user-user interaction (see Table 1). It should be noted that two members of the research team were invited during the coding to ground the data in order to ensure the reliability of the qualitative research. Additionally, they voluntarily adjusted names and quantity of topics they recognized, and then carried out reliability test by SPSS 22.0 on final results-we got Alpha $>0.8$, a good consistency.

According to the coding results, "quality of user-user interaction" can be classified into two major categories-Connotative Quality and Peripheral Quality, of

Table 1. Interview text encoding results.

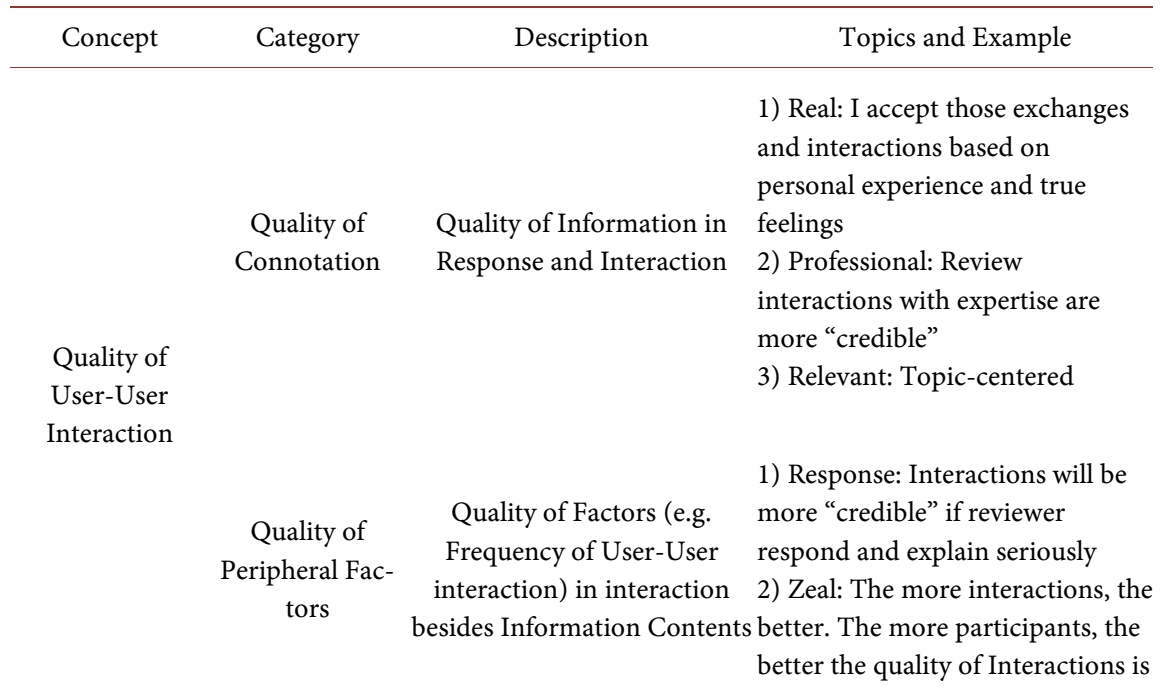


which the first one refers to the information quality of interaction, and the second one refers to quality of other factors except the information.

\subsection{Conceptual Measurement Items Designing and Factor Analyzing}

To study the validity and reliability of measures (6 in total) and dimensions of the final construct, this paper designed, distributed and retrieved questionnaires on these measures for empirical test. Only one factor (3.521) whose Eigen value is greater than 1 could be extracted from the 59 effective questionnaires via EFA, and the explained variance of all measures is $58.69 \%$. Measure PQ3 was ruled out in accordance with load statistics, and other 5 measures underwent KMO $(0.82)$ and Bartlett's Test $(p<0.05)$. The results demonstrated sound improvement in Cronbach's a (0.877). Besides, Amos2.1 was applied for CFA and amendment, and evaluation (see Table 2 and Table 3 ) was made eventually via standard load and collective fitting indices. Hence the preliminary conclusion- "quality of user-user interaction" is a first-order construct. Though the two core categories-connotative quality and peripheral quality-are deemed as a second-order model, the fitting degree of CFA result is not satisfactory. Therefore, this paper treats "quality of U2U interaction" as a first-order with two-dimensional construct in the following research.

\subsection{Information Prosumption Behavior}

Due to the similarity of Book.DouBan and the social e-commerce (both are characterized by shopping and information exchange) that Dr. Shen Lei chosed for Web 2.0 consumption behavior study, this paper directly quotes the results of the qualitative research (Shen \& Zheng, 2019) (see Table 4) as the basis of selecting and classifying the 12 measures of "prosumption behavior".

In light of the coding results, prosumption behavior is divided into three major categories-non-disseminated information interaction, disseminated information

Table 2. The significance of the path coefficient test results.

\begin{tabular}{ccc}
\hline Path & Estimate $^{2}$ & (C.R.) P \\
\hline PQ2<---C2C & 0.844 & $* * *$ \\
PQ1<---C2C & 0.619 & $* * *$ \\
CQ3<---C2C & 0.687 & $* * *$ \\
CQ1<---C2C & 0.921 & $* * *$ \\
\hline
\end{tabular}

Note: ${ }^{* *} p<0.001$ refers to statistically highly significant; (1) C.R. equals to the value of $t$; (2) Estim ate refers to loading coefficient after normalization.

Table 3. Fitting index test results.

\begin{tabular}{lcccccccc}
\hline $\begin{array}{l}\text { Fitting } \\
\text { Indices }\end{array}$ & CMIN & DF & $P$ & CMIN/DF & GFI & RMR & SRMR & RMSEA \\
\hline Results & 1.156 & 2 & 0.561 & 0.578 & 0.990 & 0.011 & 0.000 (close to 0) & 0.000 (close to 0) \\
\hline
\end{tabular}


Table 4. Grounded theory analysis and summary.

\begin{tabular}{|c|c|c|c|}
\hline Construct & Range & Description & Example \\
\hline \multirow{13}{*}{$\begin{array}{c}\text { Prosumption } \\
\text { Behavior }\end{array}$} & & $\log$ in \\
\hline & \multicolumn{2}{|c|}{ Non-Disseminated Limited in the dissemination of user } & Browse \\
\hline & Information & behavior, but still able to increase & \\
\hline & Interaction & platform traffic and loyal clients & Add to Favorite \\
\hline & & & Thumb-up \\
\hline & \multirow{6}{*}{$\begin{array}{l}\text { Disseminated } \\
\text { Information } \\
\text { Production }\end{array}$} & \multirow{6}{*}{$\begin{array}{l}\text { Contents that platforms } \\
\text { depend on are generated and } \\
\text { disseminated by users }\end{array}$} & Share \\
\hline & & & \\
\hline & & & Review \\
\hline & & & Generate Business \\
\hline & & & and Social Information \\
\hline & & & Forward \\
\hline & Commodity & Users purchase & Customize Commodities \\
\hline & Consumption & commodities and make deals & Purchase \\
\hline
\end{tabular}

production and commodity consumption. Among them, the first two are classified based on information consumption and production. Non-disseminated information interaction is a behavior which users will log in, browse and study without proactive dissemination. But these users still contribute to the traffic of information by persistent usage. In comparison, users of disseminated information production contribute more to the dissemination of information. Besides the aforesaid two sub-behaviors, users could also go shopping directly online, which falls into the third category-commodity consumption.

Based on the above results, factor analysis was conducted on 84 effective sub-questionnaires around 12 measures. As a result, $\mathrm{KMO}=0.854$; Bartlett's Test: sig $<0.01$. According to EFA, there are 3 factors whose Eigen values are greater than 1, and accumulative explained variances around $72.6 \%$. In addition, CFA shows that each load coefficient or path coefficient is significant and greater than 0.6. Hence the preliminary conclusion: prosumption behavior is a second-order three-dimensional construct, and collective fitting indices of such measure model are quite ideal (CMIN/df $\approx 1.680$; SRMR $\approx 0.00$; GFI $\approx 0.872$; RMSEA $\approx 0.091$; CFI $\approx 0.946$ ).

All standard path coefficients (load) in the fitting results of CFA are significant. Each corresponding AVE of latent variables is greater than 0.5, and CR 0.7, indicating that measures enjoy high convergent validity. Meanwhile, square root of each corresponding AVE of latent variables is greater than the correlation coefficient between the relevant latent variable and other variables. Hence prosumption behavior has relatively high discriminate validity, and should be a higher-order three-dimensional construct.

\section{Study 2}

\subsection{Conceptual Framework and Hypotheses}

By means of literature review based on user-user interaction in Web 2.0, this 
paper proposes the UGC adoption model (see Figure 2). Unlike the information adoption model centered on e-mail as the major channel for information exchange in Web 1.0, such model pays closer attention to the interaction. Moreover, grounded on the S-O-R model, this paper deems perceived usefulness and adoption willingness as users' (organism) primary perception and willingness, and prosumption behavior as the end of the model. Additionally, this paper studies the mediating effect that UGC adoption willingness yields on both UGC perceived usefulness and prosumption behavior.

According to ELM, when an individual is able and willing to analyze the received information from exchange, the quality of such information will determine the perceived usefulness of the very individual, and further affect the degree of his/her being influenced by the information, in other words, adoption willingness. Therefore, ELM treats information quality as the critical cue that affects the perceived usefulness towards information in the above context. However, the disparity in research objects also brings the variation in objects of information quality. This paper, comprehensively considering the actual situation of such research, selects dimensions related to the quality of UGC: information integrity of UGC, content relevance and review timeliness. In addition, based on the previous research, this paper proposes Hypothesis 1:

H1: UGC quality has a significant positive influence on perceived usefulness of UGC.

In ELM, peripheral cues are opposite to critical cues. In other words, when an individual is unable or unwilling to analyze the received information from exchange, then the peripheral cues (except critical cues) will determine the perceived usefulness, and further affect the degree of his/her being influenced by the

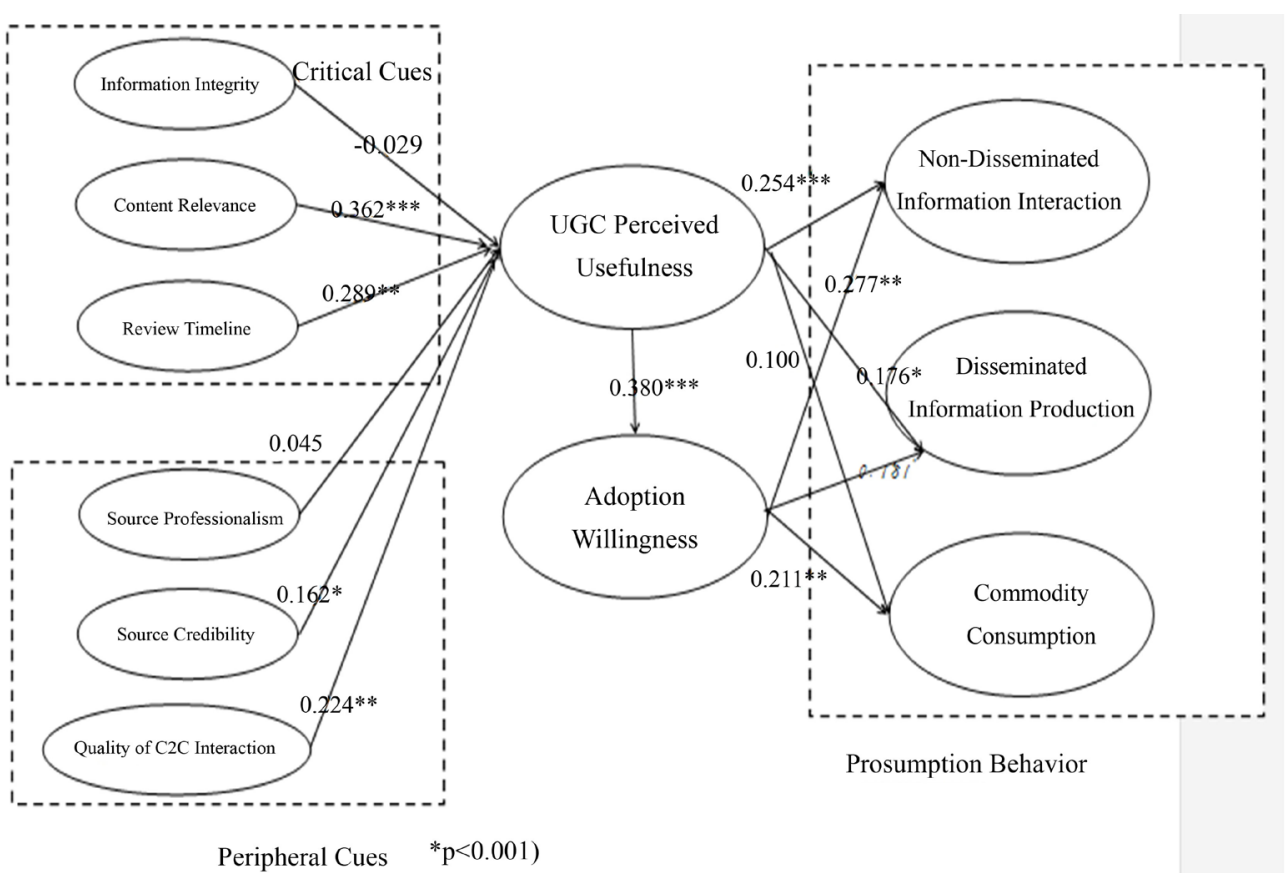

Figure 2. The user-generated content adoption model in Web 2.0 environment. 
very information. Petty and Cacioppo (Petty and Cacioppo, 1986), defined peripheral cues as information-related factors (e.g. source credibility) apart from contents, and further certified via empirical research that the source credibility has a positive influence on perceived usefulness. In general, also based on empirical research, scholars (Weiss, Lurie, \& Macinnis, 2008) measure the source credibility by two dimensions-competence and trustworthiness (Sussman and Siegal, 2003), (Weiss, Lurie, \& Macinnis, 2008). In consequence, this paper also deems the above two important. Besides, based on the interaction feature in Web 2.0, this paper also includes quality of user-user interaction in peripheral cues, and thus proposes Hypothesis 2 and 3:

$\mathrm{H} 2$ : Source credibility has a significant positive influence on UGC perceived usefulness.

H3: Quality of user-user interaction has a positive influence on UGC perceived usefulness.

Moreover, based on adoption and informational influence, Sussman established the information adoption model in certain organizations where e-mail is the major channel for information exchange in 2003. Sussman also certified that under the influence of external stimuli (critical cues and peripheral cues), perceived usefulness will positively affect the generation of information adoption willingness of individuals. To be more specific, in accordance with TRA (Fishbein \& Ajzen, 1975) and TAM (Davis, 1989), external stimuli (information quality, source credibility and others) will trigger users' organism reaction, which would directly affect the final behavior. Meanwhile, this paper argues that users' (organism) psychological judgment on the value of information will in the same way directly affect the prosumption behavior later on. Based on above discussions, this paper proposes the following hypotheses:

H4: UGC perceived usefulness has a positive influence on the generation of UGC adoption willingness.

H5: UGC perceived usefulness has a positive influence on users' prosumption behavior.

Last, based on literature review on the information adoption model, this paper finds out that most results deem "information adoption" as the motive or willingness for certain behavior, and has discussed factors affecting such motive or willingness. Besides, previous studies mostly focused on the antecedent variables of the motive or willingness but not on the final behavior. In that case, this paper selects the impact that the motive or willingness of UGC adoption yields upon consequent user behaviors as one of the core topics. The research 1 helps us define user behavior as prosumption behavior which is measured by three dimensions-non-disseminated information interaction, disseminated information production and commodity consumption. And we hereby propose the following hypotheses:

H6: UGC adoption willingness has a positive influence on users' prosumption behavior.

H7: UGC adoption willingness has a mediating effect between UGC perceived 
usefulness and prosumption behavior.

\subsection{Data Collection and Results Analysis}

We distributed our Likert Scale 5 point questionnaires to both online and offline users of Book.DouBan. Ultimately, we retrieved 203 effective questionnaires (valid rate: $94.9 \%$ ) after official survey.

First, kurtosis and skewness of sample data are both less than 3; all data conform to multivariate normal distribution; parameter estimation is possible via maximum likelihood estimation.

But reliability and validity analyses are necessary before empirical analysis, so as to lay a foundation for judging whether measures could effectively link with latent variances for further amendments. Reliability test is designed to observe the purification of measures by CITC via reliability analysis of SPSS22.0, for the purpose of Cronbach's a test. However, the results haven't been amended even after ruling out IR1, SC1 and PQ1. Therefore, measures stay intact and Cronbach's $\alpha$ is 0.919 .

After that, this paper goes on to judge the convergent validity of psychometric properties (i.e. Cronbach's $\alpha$, AVE and CR) of each theoretical construct. During this period, load coefficients of normalized factors to each latent variance are greater than 0.6; CR 0.7; AVE greater than both 0.5and the correlation coefficients between AVE and different constructs. These results to a degree demonstrate the high convergent validity and discriminative validity of the data sample.

Results of path analysis: $\chi^{2}=1251.237, \chi^{2} / \mathrm{df}=2.564$; RMSEA $=0.083$, SRMR $=0.069 . \chi^{2}$ statistic, besides being inconsistent with the ideal fitting of the hypothetical model, is also prone to rejecting the entire model in case of sudden increase of sample size, reasons of which are that $\chi^{2}$ statistic is usually sensitive to the overall data and DOF (degree of freedom) varies with the complexity of the model. Hence the solution: information provided by other fitting indices should be taken into consideration. Generally, $\chi^{2} / \mathrm{df}$ of the structural model is less than 3; SRMR less than 0.08; RMSEA, not less than but close to 0.08, is within the tolerance interval. Moreover, CFI (0.89) and GFI (0.876) among relative fitting indices are of reference significance to judging the fitting of the model. To sum up, the aforesaid two fitting indices and the fitting of the hypothetical model at large are within the tolerance interval (greater than or close to 0.9). See Figure 2 for path coefficient.

The results show that $\mathrm{H} 1, \mathrm{H} 2$ and $\mathrm{H} 5$ are supported partially; and $\mathrm{H} 3, \mathrm{H} 4$ and H6 are supported fully.

In the end, this paper applies Bootstrap repeated sampling $(\mathrm{N}=500)$ for significance test on the mediating effect of information adoption willingness. According to the sampling, the $2.5^{\text {th }}$ and $97.5^{\text {th }}$ percentiles are estimated of $95 \%$ confidence interval of mediating effect. And it turns out that the number 0 isn't included in the $95 \%$ confidence interval of these path coefficients, indicating significant mediating effect. Hence, H7 is supported. 


\section{General Discussion}

\subsection{Theoretical Contributions}

According to the research results, this paper not only revealed quantitatively the nature of prosumption behavior and quality of user-user interaction, but also figured out the antecedents and consequences of information adoption.

\subsection{What Is Prosumption Behavior?}

Based on the qualitative research by the team of Dr. Shen (Shen \& Zheng, 2019) on the consumer behavior in Web 2.0 social e-commerce, this paper, via quantitative analysis, affirms the essential feature of prosumption behavior-combination of production and consumption. Meanwhile, this study shows because it is imparity for the participation and sharing of prosumers on Internet platforms, the prosumption behavior consists of three sub-conrtucts, non-disseminated information interaction, disseminated information production and commodity consumption. In Web 2.0, users purchase commodity by traditional consumption behavior on the platforms, they would collect their favorite information and forward it to others, and even proactively partake in information re-production, which overturns the traditional consumption behaviors in Web 1.0. In other words, in Web 2.0, consumers (prosumers, to be more specific) will not only be satisfied with obtaining contents of their zealous platforms, but also purchase commodities in accordance with the business information from merchants. Instead, users are especially willing to interact with others to share information via the platform, and even reproduce contents and spread to the public.

\subsection{How to Regard as Interaction Quality of User-User?}

Qualitative research illustrates that users of social network sites pay attention to contents authenticity, in the meantime, they analyze the exchanged information according to people's own experience or others' feedback, so as to determine the quality of interaction. The result, users believe that it is trustworthy to get interactions according to real experience. In addition, a few users have always been focusing on the topics of interactions; they believe that it is higher quality and representativeness for them to be interested in. In the end, users will believe completely that the interaction is higher quality and then they accept reviewers' feedback in time and respond to other users. Furthermore, the stronger the interaction is in conflicts of certain question, the more "credible" the whole interaction process is.

\subsection{How to Understand User Information Adoption?}

In Web 2.0, the UGC perceived that usefulness is under the influence of various factors. The critical cue (if UGC is linked with the topic or not), and peripheral cues (UGC provider credibility, interaction among other users) will directly affect users' UGC perception. Unexpectedly, UGC integrity in critical cues is no promotion to users' determining the usefulness instead. The reason as follows: 
compared with lengthy information that requires more time and attention, users in today's fast-pace world prefer concise information. At the same time, source professionalism in peripheral cues serves no longer as the influencing factor of users' determination on UGC perceived usefulness. Instead, users care about whether the UGC provider is trustworthy, so they tend to accept easy-to-understand contents rather than professional stuff on social networking platforms. Moreover, UGC perceived usefulness cannot affect the direct purchase behavior of individuals in spite of its positive influences-promoting the generation of adoption willingness or motive of UGC, directly affecting users' participation in information interaction or production. The reason may be that people still tend to purchase on other e-commerce platforms rather than social networking ones. On the one hand, in the social network, users mainly play the role of "prosumer" who conducts both production and consumption of information. On the other hand, UGC adoption willingness, the key influencing factor that promotes users' subsequent prosumption behavior, which is generated after users' self-judgment on UGC perceived usefulness, thereby influencing whether users would proactively participate in the prosumption activities of the platform.

\section{Conclusion}

This paper holds the view that on both social and e-commerce platforms, information quality and provider credibility will still affect the perceived value of users, and further indirectly affect the progress of platform traffic and brand word-of-mouth. Moreover, user-user interaction in Web 2.0 will gradually be significance and even become the soft power in the future platform competition. Therefore, websites should adhere to monitoring the information quality and certificate of users, expand the space for exchanges instead of reaping profits by advertising and selling products. In general, users are no longer limited by outdated technologies or channels in information retrieval. Nowadays they are able to obtain information via Internet browsers, or to understand commodities via information from merchants. Therefore, on both social networking or e-commerce platforms, over-dependence on cash flow from direct marketing may be the major obstacle of today's enterprises. Solutions to questions such as how to provide users with information or service of real value, and how to facilitate the user-user interaction, serve as the key to the long-term development of platforms.

This paper studies the prosumption behavior in social networking sites. In Internet environment, enterprises provide users information to use, learn, deal with and produce any content. Similarly, enterprises in the Internet economy also provide users the entire network platform and all the relevant information contents. It is impossible in traditional economic environment, in that few enterprises it would generously provide clients with all the instruments of production. But what's intriguing is that in Web 2.0, Internet enterprises can grant users full access to raw materials and instruments without any worry, meanwhile reaping the final financial value produced by prosumers. It is because via profit- 
ing by the information or contents, enterprises take back the potential profitability hidden in the information. For instance, Coca-Cola launched crowd sourcing advertising competition via social networking sites, and eventually achieved 8 times more output thanks to its champion slogan. OhMyNews, famous "mass media" of Korea, raised the proportion of online news to $80 \%$ thanks to its 26,000 readers... In Web 2.0, prosumption behavior still enjoys huge potential to be exploited. Therefore, how to transform the prosumption behavior into a brand-new business model in favor of future development is a key question for enterprises to probe into.

\section{Conflicts of Interest}

The authors declare no conflicts of interest regarding the publication of this paper.

\section{References}

Cheung, C. M. K., \& Thadani, D. R. (2012). The Impact of Electronic Word-of-Mouth Communication: A Literature Analysis and Integrative Model. Decision Support Systems, 54, 461-470. https://doi.org/10.1016/j.dss.2012.06.008

Cheung, C. M. K., Lee, M. K. O., \& Rabjohn, N. (2008). The Impact of Electronic Word-of-Mouth: The Adoption of Online Opinions in Online Customer Communities. Internet Research, 18, 229-247. https://doi.org/10.1108/10662240810883290

Chevalier, J. A., \& Mayzlin, D. (2006). The Effect of Word of Mouth on Sales: Online Book Reviews. Journal of Marketing Research, 43, 345-354. https://doi.org/10.1509/jmkr.43.3.345

Davis, F. D. (1989). Perceived Usefulness, Perceived Ease of Use, and User Acceptance of Information Technology. MIS Quarterly, 13, 319-340. https://doi.org/10.2307/249008

Fishbein, M., \& Ajzen, I. (1975). Belief, Attitude, Intention and Behaviour: An Introduction to Theory and Research. Philosophy \& Rhetoric, 41, 842-844.

Hu, N., Pavlou, P. A., \& Zhang, J. (2006). Can Online Word-of-Mouth Communication Reveal True Product Quality? Experimental Insights, Econometric Results, and Analytical Modeling. SSRN Electronic Journal, 2006. https://doi.org/10.2139/ssrn.2380731

Lan, J., Ma, Y., Zhu, D. J., Mangalagiu, D., \& Thornton, T. F. (2017). Enabling Value Co-Creation in the Sharing Economy: The Case of Mobike. Sustainability, 9, 1504. https://doi.org/10.3390/su9091504

Li, C. X., \& Hong, Y. L. (2008). The Effect of Culture in User-Generated Content. SSRN Electronic Journal, 2008, 49-62.

O'eilly, T. (2005). What Is Web 2.0: Design Patterns and Business Models for the Next Generation of Software.

http://www.oreillynet.com/pub/a/oreilly/tim/news/2005/09/30/What-is-web-20.Html

Park, D.-H., Lee, J., \& Han, I. (2007). The Effect of On-Line Consumer Reviews on Consumer Purchasing Intention: The Moderating Role of Involvement. International Journal of Electronic Commerce, 11, 125-148. https://doi.org/10.2753/JEC1086-4415110405

Petty, R. E., \& Cacioppo, J. T. (1986). Communication and Persuasion: Central and Peri- 
pheral Routes to Attitude Change (pp. 58-76). New York: Springer-Verlag.

Rayna, S., \& Striukova, L. (2015). Open Innovation 2.0: Is Co-Creation the Ultimate Challenge? International Journal of Technology Management, 69, 38-53. https://doi.org/10.1504/IJTM.2015.071030

Ritzer, G. (2014). Prosumption: Evolution, Revolution, or Eternal Return of the Same? Journal of Consumer Culture, 14, 3-24. https://doi.org/10.1177/1469540513509641

Ritzer, G. (2015). Prosumer Capitalism. The Sociology Quarterly, 56, 413-445. https://doi.org/10.1111/tsq.12105

Shah, S. H. H., Shen, L., Hussain, S. T., \& Mariam, S. (2019). How Consumer Perceived Ethicality Influence Repurchase Intentions and Word-of-Mouth? A Mediated Moderation Model. Asian Journal of Business Ethics, 2019. https://doi.org/10.1007/s13520-019-00096-1

Shen, L., \& Zheng, Z. Y. (2019). Web 2.0 Prosumption: Essence and the Value Logic. Forecast, No. 3, 91-96.

Shen, L., \& Zheng, Z. Y. (2014). The Research of Online Consumption Behavior and the Construction of the Dual-Track Model of Online Consumption Decision-Making. Foreign Economics and Management, 36, 53-61.

Sussman, S. W., \& Siegal, W. S. (2003). Informtional Influence in Organizations: An Integrated Approach to Knowledge Adoption. Informational Systems Research, 14, 47-65. https://doi.org/10.1287/isre.14.1.47.14767

Tan, W.-K., \& Lee, B.-Y. (2018). Investigation of Electronic-Word-of-Mouth on Online Social Networking Sites Written by Authors with Commercial Interest. Online Information Review, 43, 462-480.

Tsao, W.-Y. (2017). Building the Long Bridge between Visitors and Customers through Online General Reviews. Online Information Review, 42, 1468-4527.

Weiss, A. M., Lurie, N. H., \& Macinnis, D. J. (2008). Listening to Strangers: Whose Responses Are Valuable. How Valuable Are They, and Why? Journal of Marketing Research, 45, 425-436. https://doi.org/10.1509/jmkr.45.4.425

Wolf, M., \& McQuitty, S. (2015). Creating Value through Prosumption: An Empirical Analysis of DIY Practice. Proceedings of the 2010 Academy of Marketing Science (AMS) Annual Conference, 5, 26-29. https://doi.org/10.1007/978-3-319-11797-3_54

Yeh, C.-H., \& Wang, Y.-S. (2017). Investigating Online Consumers' Responses to Product Presentation Modes. Internet Research, 2017, 2.

Zhao, Y., Chen, Y. W., Zhou, R. X., \& Ci, Y. P. (2019). Factors Influencing Customers' Willingness to Participate in Virtual Brand Community's Value Co-Creation: The Moderating Effect of Customer Involvement. Online Information Review, 43,440-461. https://doi.org/10.1108/OIR-08-2017-0232

Zhu, D. H., Chang, Y. P., \& Luo, J. J. (2016). Understanding the Influence of C2C Communication on Purchase Decision in Online Communities from a Perspective of Information Adoption Model. Telematics and Informatics, 33, 8-16.

https://doi.org/10.1016/j.tele.2015.06.001 